\title{
El lento, aunque inexorable, desmembramiento del señorío de Zinacantán'
}

Juan Pedro Viqueira

El Colegio de México

A Jan Rus

El municipio de Zinacantán, ubicado en la región de Los Altos de Chiapas, es sin duda una de las comunidades indias más estudiadas por los antropólogos del mundo entero. El proyecto de investigación realizado por la universidad de Harvard (el más importante de todos) produjo en sus primeros 20 años de existencia, 27 libros y monografías, 21 tesis de doctorado, 33 tesis de licenciatura, dos novelas, una película, casi 400 informes y un gran número de artículos. La gran mayoría de estos trabajos tratan exclusivamente del municipio de Zinacantán. ${ }^{2}$ Sin embargo sabemos muy poco de la historia de Zinacantán.

Esta aparente paradoja se explica fácilmente si tomamos en cuenta que Evon Z. Vogt, quien dirigió durante más de 20 años el proyecto de la universidad de Harvard, ${ }^{3}$ pensaba que desde el siglo $\mathrm{X}$ la historia se había detenido en Zinacantán, en particular, y en Los Altos de Chiapas, en general. Según él, la cultura de los indios no había conocido ningún cambio importante desde aquella fecha:

Zinacantán ejemplifica un cierto número de hechos fundamentales de la subsistencia, del patrón de poblamiento y de la organización social y ceremonial, provenientes de los primeros periodos de la cultura maya [...] Pienso que es bastante probable que el Petén, los Cuchumatanes y Los Altos de Chiapas [...] quizá constituyan la región más importante para el entendimiento de la cultura maya

1 Una primera versión más corta de este trabajo fue publicada en francés: "Le lent, bien qu'inexorable, démembrement de la seigneurie de Zinacantán (Chiapas, Mexique)", Genèses. Sciences sociales et histoire, 32, Septiembre 1998, pp. 66-85.

${ }^{2}$ E. Z. Vogt, Bibliography of the Harvard Chiapas Project, p. 30. ${ }^{3}$ Sobre la historia de este proyecto de investigación, véase E. Z. Vogt, Fieldwork among the
Maya. 
en su forma relativamente imperturbada, en diferentes escalas de tiempo. ${ }^{4}$

Partiendo de esta premisa, Vogt extrapoló los datos tomados de los actuales pueblos de lengua tzotzil a la civilización maya del periodo clásico, llegando a afirmar que en esos tiempos los habitantes de las ciudades no formaban un grupo social distinto de los campesinos. Según él, eran los propios campesinos quienes desempeñaban las funciones de sacerdotes en forma rotativa y por cortos periodos de tiempo. Sólo algunos oficios que requerían de un dominio técnico preciso - músico, artesano- eran desempeñados por especialistas de tiempo completo, quienes sin embargo estaban subordinados a los campesinos que fungían momentáneamente como sacerdotes principales. ${ }^{5}$ Huelga decir que todas éstas afirmaciones han sido desmentidas por las recientes investigaciones arqueológicas.

Para poder demostrar estas descabelladas ideas, los antropólogos culturalistas se dedicaron a minimizar las transformaciones acaecidas durante más de cuatro siglos - diez, en el caso extremo de Vogt—, colocando así a los indios al margen de la historia. Estos no eran sino fósiles vivientes, frágiles testigos de un pasado glorioso. Su situación presente, sus problemas económicos, políticos, sociales y religiosos carecían de todo interés para estos investigadores. El estudio de las comunidades indias actuales no tenía otra finalidad que la de permitir un mejor conocimiento de las civilizaciones prehispánicas. En las etnografías que se escribieron bajo el influjo de esas ideas, todos los rasgos culturales que a juicio de los antropólogos tenían un origen reciente eran cuidadosamente omitidos, dando así una imagen totalmente falseada de la vida de los grupos indios de Chiapas.

El razonamiento que seguía esta corriente antropológica era - por decir lo menos - circular. Empezaba por afirmar una continuidad cultural de las comunidades indias desde la época prehispánica hasta nuestros días. Este postulado les permitía "reconstruir" la sociedad prehispánica maya con base en los datos recogidos en el campo. Finalmente "demostraban" que aquella sociedad se parecía mucho a las comunidades indias actuales.

El error de la antropología culturalista norteamericana no radicaba tanto en un supuesto desinterés por la historia, sino más bien en presentar como verdades históricas incontrovertibles hipótesis simplistas que no eran nunca confrontadas con documento o estudio histórico alguno.

${ }^{4} \mathrm{E}$. Z. Vogt, "Algunos aspectos de patrones de poblamiento y de la organización ceremonial de Zinacantán", pp. 80-81.

"Ibid, p. 82. 
Hubo, claro está, algunos antropólogos del proyecto Harvard - como Jan Rus y Robert Wassertron- ${ }^{6}$ que criticaron esta estrecha visión y se interesaron por la verdadera historia de los indios de Los Altos. Pero el director del proyecto los anatematizó, acusándolos de ser unos marxistas ortodoxos para los cuales la cultura no era sino un epifenómeno de la lucha de clases.? Ciertamente las conclusiones a las que estos disidentes llegaban resultaban por lo menos incómodas, si no es que francamente subversivas para la antropología culturalista.

En efecto, estos investigadores demostraban que el sistema de cargos de Zinacantán (cuyo estudio, se decía, era la aportación más importante del proyecto Harvard a la teoría antropológica) no era un mecanismo prehispánico de redistribución de la riqueza que, al garantizar la cohesión de las comunidades, había permitido su supervivencia. Por el contrario, el sistema de cargos en Zinacantán había aparecido en el siglo XIX, tras la desaparición de las cofradías coloniales. Los ingresos de los indios que trabajaban varios meses al año en las plantaciones de café del Soconusco, habían hecho posible que surgiera este nuevo sistema de financiamiento de las fiestas religiosas. ${ }^{8}$

Por las mismas fechas en que algunos antropólogos norteamericanos tomaban distancia con respecto a los axiomas de la teoría culturalista, otros investigadores, mexicanos y extranjeros, empezaron a estudiar en forma sistemática la historia de las regiones indias de Chiapas utilizando nuevos enfoques, algunos de ellos de una gran originalidad y riqueza. ${ }^{9}$ Sin embargo, la historia de Zinacantán durante la época colonial no ha sido estudiada hasta ahora con cierta precisión, a pesar de que esta comunidad presentaba (y de hecho sigue presentando) rasgos sumamente originales en comparación con otros municipios de Los Altos de Chiapas. ${ }^{10}$

\footnotetext{
${ }^{6} \mathrm{~A}$ estos dos nombres habría que añadir otros más, entre ellos el de Robert M. Laughlin que ha publicado diversos documentos de gran importancia sobre la historia de los indios de Chiapas, acompanados de introducciones críticas muy valiosas. Por otra parte George Collier siempre ha ubicado sus análisis de la vida social de los indigenas zinacantecos en el contexto de las transformaciones económicas y politicas que ha conocido México durante las últimas décadas.

' E. Z. Vogt, Fieldwork among the Maya, p. 364.

"). Rus y R. Wasserstrom, "Civil-Religious Hierarchies in Central Chiapas".

${ }^{9}$ No es posible mencionar aquí todos los estudios históricos recientes sobre el Chiapas colonial. Algunos de los más importantes son: D. Aramoni Calderón, Los refugios de lo sagrado; G. Lenkersdorf, Génesis histórica de Chiapas; M. H. Ruz, Copanaguastla en un espejo; y "Los rostros de la resistencia"; y J. de Vos, La paz de Dios y del Rey; y Vivir en frontera.

${ }^{10} \mathrm{La}$ historia de Zinacantán a partir de la Independencia ha sido en cambio estudiada por $\mathrm{R}$. Wasserstrom, Clase y sociedad en el centro de Chiapas, pp. 129-274.
} 
Pero para poder realizar este estudio es necesario antes que nada atacar desde sus raíces la ilusión esencialista propagada por la antropología culturalista y que ahora es paradójicamente retomada por muchos intelectuales indianistas. No basta con reconocer que la cultura de los zinacantecos ha conocido importantes transformaciones a lo largo del tiempo. Es necesario ir más allá y criticar incluso la idea de que Zinacantán es una unidad políticoterritorial a la que le han sucedido "cosas", que pueden haber dejado huellas y cicatrices profundas y duraderas, pero que no han alterado su identidad misma, ni roto su continuidad histórica. En efecto, no es posible estudiar la historia de Zinacantán a través de los siglos, desde la época prehispánica hasta nuestros días, porque la actual comunidad de Zinacantán es una creación colonial, un resultado de las formas de control político y territorial puestas en práctica por las autoridades españolas. De lo que se trata, por lo tanto, es de escudriñar la lenta emergencia de un efímero sujeto colectivo, de mostrar los jalones de su compleja construcción histórica.

Este es, justamente, el propósito de este artículo: Narrar cómo los espańoles hicieron añicos el enorme señorío prehispánico de Zinacantán y cómo, de unos cuantos de estos pedazos, nació y creció un nuevo sujeto colectivo: la república de indios de Zinacantán, que más adelante, en el periodo independiente, daría lugar al actual municipio de Zinacantán.

\section{La construcción del señorío de Zinacantán}

Los actuales zinacantecos son hablantes del tzotzil, una de las más de 20 lenguas que conforman la gran familia lingüística mayanse. Dentro de esta familia, los especialistas ubican el tzotzil en el grupo denominado cholano. De acuerdo con los estudios arqueológicos y glotocronológicos, los hablantes de cholano habrían llegado al Macizo Central de Chiapas en el transcurso del segundo milenio antes de Cristo, provenientes de la Selva del Petén.

Algunos de estos migrantes se quedaron en la Selva Lacandona y en las partes bajas del Macizo Central. En estas regiones, el cholano, tras un largo proceso de diferenciación, dio lugar al chol, al chontal, al chortí y al choltí. Los demás migrantes continuaron su camino hacia el norte y su lengua evolucionó hasta convertirse en el tzeltalano. A principio de nuestra era, llegaron a la Depresión Central después de haber desplazado hacia el oeste a los zoques que ocupaban la región. Entre los siglos $\mathrm{V}$ y $\mathrm{X}$, su lengua se fue escindiendo hasta dar nacimiento al tzeltal $y$ al tzotzil."

\footnotetext{
"M. Tejada Bouscayrol y J. E. Clark, "Los pueblos prehispánicos de Chiapas", pp. 325-327; y R. M. Adams, "Patrones de cambio de la organización territorial", p. 50.
} 
A la llegada de los españoles, las unidades políticas no coincidían con los grupos lingüísticos existentes. Tanto tzotziles, como tzeltales estaban divididos en varios señoríos enfrentados unos a otros. ${ }^{12}$ Por otra parte, las guerras de conquista habían llevado a varios de éstos a someter a pueblos vecinos de habla distinta a la propia. ${ }^{13}$

Los antiguos zinacantecos empezaron a diferenciarse de los demás grupos vecinos de habla tzotzil y a adquirir una identidad propia cuando se encontraban asentados en el extremo sur de Los Altos de Chiapas, sobre la pendiente abrupta que separa el Macizo Central del Valle del Río Grande de Chiapa. Se trata de una región extremadamente accidentada en la cual, en un tramo de apenas unos cuantos kilómetros, el terreno desciende desde los 2,400 metros sobre el nivel de mar en lo alto de las montañas que rodean el Valle de Jovel -en donde se encuentra hoy en día San Cristóbal de Las Casas-a los $600 \mathrm{msnm}$ en las márgenes del Río Grande. Según declararon los zinacantecos a mediados del siglo XVI, en un pleito que los opuso a sus consuetudinarios enemigos los chiapanecas por el control de unas tierras, sus "Zacualpas", es decir sus asentamientos originarios, se encontraban en esa zona. Los anteriores pobladores, los chalchihuitecos (seguramente de lengua tzeltal) les habían "cedido" sus tierras, antes de mudarse al valle del Río Grande. ${ }^{14}$

Con el tiempo, los zinacantecos lograron agrandar su territorio hasta constituirse en el señorío más importante de la región, sólo superado por el de los chiapanecas. ${ }^{15}$ A principios del siglo XVI, el territorio que estaba bajo el control de los zinacantecos era sumamente extenso y estaba conformado por un gran número de asentamientos humanos. ${ }^{16}$ Se iniciaba en Osumacinta y

${ }^{12}$ E. E. Calnek, "Highland Chiapas Before The Spanish Conquest", pp. 3-5. El conquistador Diego Godoy, "Relación hecha por ... a Hernando Cortés", p. 467 dijo refiriéndose a Chiapas: "Todos los pueblos de esta tierra son de esta manera, que tienen guerra unos con otros".

${ }^{13}$ Véasen algunos ejemplos de ello en E. E. Calnek, "Los pueblos indígenas de las tierras altas", pp. 115, 122, 124 y 129-130; (Probanza de María Magdalena Tenezacatlán] en ). de Vos, Vivir en frontera, pp. 207-208; B. Díaz del Castillo, Historia verdadera de la conquista de la Nueva España, cap. CLXVI, pp. 419-424; A. Megged, "Accommodation and Resistance of Elites in Transition", pp. 482-483, nota 17; y J. de Vos, La paz de Dios y del Rey, p. 358.

14 C. Navarrete, The Chiapanec. History and Culture, pp. 101-102.

${ }^{15}$ Hacia 1545, fray Tomás de la Torre consideraba que los pueblos más ricos de Chiapas eran Chiapa, Zinacantán, Copanaguastla y algunos de los Zoques, cuyos nombres no menciona: $\mathrm{Fr}$. A. Remesal, Historia general de las Indias Occidentales ..., libro VIII, cap. XVII, vol. II, p. 207; y Fr. F. Ximénez, Historia de la provincia de San Vicente de Chiapa y Guatemala ... (1977), libro II, cap. LVIII, p. 509.

${ }^{16}$ Los conquistadores hicieron referencia en varias ocasiones a asentamientos sujetos a 
Chicoasén, a orillas del Río Grande, aguas abajo del Cañón del Sumidero, ${ }^{17} \mathrm{e}$ incluía la Meseta de Ixtapa, ${ }^{18}$ el valle actual de Zinacantán ${ }^{19}$ y la mitad occidental del Valle de Jovel. ${ }^{20}$ Se extendía, luego, por la abrupta vertiente meridional del Altiplano de Chiapas, abarcando el pueblo de Totolapa y lógicamente las cercanas minas de ámbar. Este territorio terminaba en los pueblos de Macuil-Suchitepeque y Quetzaltenango, que se encontraban cerca del señorío de Copanaguastla, tal vez en el Valle del Río Grande, tal vez un poco más en alto, en la vertiente sur del Macizo Central. ${ }^{21}$ Además, en un documento de mediados del siglo XVI, los indios descendientes del señorío de Pontehuitz (cuya cabecera daría lugar en la época colonial a los pueblo de Santa Marta Xolotepec y María Magdalena Tenezacatlán), que abarcaba extensas áreas de las Montañas Chamulas, del Valle de Huitiupán y de los Valles de Jitotol, parecen identificarse con los zinacantecos. ${ }^{22}$

Zinacantán: D. Godoy, "Relación hecha por ... a Hernando Cortés", pp. 465 y 467.

Segứn un documento de 1598, Zinacantán todavía tenía seis sujetos que eran Chiacitepeque, Maycuchutepeque [Macuil-Suchitepeque], Xicaltenango, Anqueytepeque, Tultepeque y Ochiatulita: A. Megged, "Accommodation and Resistance of Elites in Transition", p. 489, nota 43. Es probable que antes de la conquista su número fuera mucho mayor como lo señalan otras fuentes a las que haremos referencia más adelante.

${ }_{17}$ E. E. Calnek, "Los pueblos indigenas de las tierras altas", pp. 122 y 124-125.

18 Fr. F. Ximénez, Historia de la provincia de San Vicente de Chiapa y Guatemala ... (1977), libro II, cap. XLIV, p. 376.

Aunque en 1571, los chiapanecas afirmaron haber sido ellos los dueños de las salinas de Ixtapa, los indios de este último pueblo aseguraron haberlas recibido de los pobladores originales, asentados en Uselo, que se habían retirado de la región para ir a vivir a Tabasco: C. Navarrete, The Chiapanec. History and Culture, pp. 100-102.

${ }^{10}$ Este parece ser el valle que describe D. Codoy, "Relación hecha por ... a Hernando Cortés", p. 465.

${ }^{20}$ Según la memoria oral de los indios de Los Altos el valle de Jovel estuvo ocupado en el pasado por zinacantecos y chamulas.

${ }^{21}$ C. Navarrete, The Chiapanec. History and Culture, p. 103. En 1528, los zinacantecos fueron a recibir a Diego de Mazariegos a jiquipilas para pedirle ayuda para recuperar el control sobre Macuil-Suchitepeque: G. Lenkersdorf, Génesis histórica de Chiapas, p. 177.

Algunos pueblos sujetos a Zinacantán producían algodón, lo que hace suponer que se encontraban en las tierras calientes del Valle del Río Grande: E. E. Calnek, "Highland Chiapas Before The Spanish Conquest", p. 15.

Otra posibilidad es que Macuil-Suchitepeque y Quetzaltenango se encontraran en algún lugar entre los Valles de Teopisca y las Terrazas de Socoltenango. Recuérdese que cerca de Aguacatenango había un pueblo denominado Quetzaltepec, que podría ser el mismo que Quetzaltenango.

${ }^{22}$ [Probanza de María Magdalena Tenezacatlán] en J. de Vos, Vivir en frontera, pp. 207-208. 
Es importante señalar que, sin necesidad de incluir las tierras de Pontehuitz entre los dominios de Zinacantán, este señorío era plurilingüe ya que la lengua de los zinacantecos era el tzotzil, mientras que los habitantes de Osumacinta y Chicoasén eran hablantes de zoque, y probablemente los de Macuil-Suchitepeque y Quetzaltenango lo eran de tzeltal, si reparamos en su ubicación entre otros pueblos tzeltales y en los deseos "independentistas" que manifestó Macuil-Suchitepeque con respecto a su cabecera, tras la primera incursión de los conquistadores españoles. ${ }^{23}$

Gracias al control que ejercían sobre este vasto territorio, los zinacantecos lograban compensar la pobreza de la mayor parte de sus tierras, al asegurarse el acceso a una notable variedad de nichos ecológicos y a varios recursos naturales de alto valor comercial, tales como la sal de Ixtapa, el ámbar de Totolapa, las pieles de tigre, $y$ las plumas de quetzales, de azulejos y de "Ios pájaros verdes preciosos". ${ }^{24}$

Al expandir sus dominios, los tinacantecos se propusieron también mantener abierta una ruta comercial entre las Llanuras de Tabasco por un lado y el Altiplano de Guatemala y el Soconusco por el otro, que no atravesara por el territorio de los chiapanecas. ${ }^{25}$ En efecto una añeja rivalidad oponía a estos dos señoríos, que luchaban por la primacía política y militar en el área, por la posesión de la sal de Ixtapa y por el control del comercio de larga distancia. ${ }^{26}$

La Triple Alianza, cuyos comerciantes, eran constantemente atacados en el Istmo de Tehuantepec por los chiapanecas y los zapotecos, ${ }^{27}$ se propuso encontrar un camino alterno entre México-Tenochtitlán y sus lejanos dominios del Soconusco. ${ }^{28}$ Para ello, en tiempos de Ahuitzotl (1487 a 1502), envió a unos pochtecas disfrazados para que espiaran a los zinacantecos, seguramente con el fin de planear su posterior conquista. ${ }^{29}$ Esta se llevó a cabo,

\footnotetext{
${ }^{23}$ C. Lenkersdorf, Cénesis histórica de Chiapas, p. 177.

${ }^{24}$ Vida económica de Tenochtitlan. 1. Pochtecayotl, V, 5-14, pp. 68-71.

${ }^{25}$ Véase U. Köhler, "Reflections on Zinacantan's Role in Aztec Trade with Soconusco"; y J. P. Viqueira, "Le mythe des colonies préhispaniques au Chiapas central".

${ }^{20} \mathrm{Fr}$. A. Remesal, Historia general de las Indias Occidentales ..., libro V, cap. XIII, vol. I, p. 409; y libro X, cap. XVIII, vol. II, pp. 471-472; Fr. F. Ximénez, Historia de la provincia de San Vicente de Chiapa y Guatemala ... (1977), libro II, cap. XLVIII, pp. 388-389; y C. Navarrete, The Chiapanec. History and Culture, pp. 99-103.

${ }^{27}$ Vida económica de Tenochtitlan. 1. Pochtecayotl, IV, 16-18, p. 65; y B. Díaz del Castillo, Historia verdadera de la conquista de la Nueva España, cap. CLXVI, pp. 419 y 424.

${ }^{28} \mathrm{U}$. Köhler, "Reflections on Zinacantan's Role in Aztec Trade with Soconusco".

${ }^{29}$ Vida económica de Tenochtitlan. 1. Pochtecayotl, V, 1-15, pp. 68-71; y Fr. B. de Sahagún, Historia general de las cosas de Nueva España, libro IX, cap. V, vol. II, p. 552.
} 
finalmente, durante el reinado de Moctezuma II (1503 a 1520). ${ }^{30}$ Según el cronista Antonio de Herrera - fuente no siempre muy confiable- los mexicas llegaron incluso a poner una guarnición militar en Zinacantán, pero ni los conquistadores ni los primeros frailes dominicos hacen referencia a ello. ${ }^{31}$ Dado que Zinacantán no parece haber pagado tributo a la Triple Alianza, ${ }^{32}$ lo más probable es que los mexicas hayan recurrido a su poderío militar, no tanto para sojuzgar a los zinacantecos, sino más bien para garantizar el tránsito de mercancías y tributos del Soconusco por el camino que éstos controlaban. Así, la "conquista" de Zinacantán parece haber desembocado más bien en una alianza comercial y militar entre este pueblo y México-Tenochtitlán, alianza consolidada gracias al hecho de que ambas ciudades estaban enfrentadas con los chiapanecas. ${ }^{33}$

Con la caída de México-Tenochtitlán en manos de los conquistadores españoles, el delicado equilibrio de fuerzas que existía en el área entre Chiapa y Zinacantán se vio profundamente alterado. Los zinacantecos para evitar que sus enemigos hereditarios, los chiapanecas, buscaran aprovecharse de la nueva situación para atacarlos y arrebatarles parte de su territorio, decidieron aliarse con los vencedores de la Triple Alianza, sobre los que, sin duda, debían correr todo tipo de historias y leyendas. Para ello se presentaron en 1522 en la villa del Espíritu Santo (cerca del actual Coatzacoalcos) para rendir obediencia a los españoles y, seguramente, para pedirles su ayuda contra los chiapanecas. ${ }^{34}$ En 1524, tras la toma de Chiapa por parte de las huestes de Luis Marín, acudieron a esa ciudad a ofrecer sus servicios y para manifestarles, junto con otros pueblos, su alegría por el resultado de la batalla. ${ }^{35}$ Cuando unos días después, Chamula y Huixtán, tras padecer las primeras exacciones de los espańoles, se rebelaron contra éstos, los zinacantecos condujeron a los con-

${ }^{30}$ The Codex Mendo7a, vol. III, ff. 15v-16v; y Códice Chimalpopoca, 242, p. 67-68.

${ }^{31}$ A. de Herrera, Historia general de los hechos de los castellanos ..., Década IV, libro X, cap. XI, p. 220.

Fr. A. Remesal, Historia general de las Indias Occidentales ..., libro V, cap. XIII, vol. I, p. 409; y D. Juarros, Compendio de la historia del reino de Guatemala. 1500-1800, tratado I, cap. II, p. 15, reiteran esa información, pero todo parece indicar que su fuente es el propio Herrera.

32 Su nombre no aparece en la "Matrícula de Tributos" del Codice Mendoza: The Codex Mendoza, vol. III.

${ }^{3}$ Para una discusión más detallada de este punto, véase U. Kōhler, "Reflections on Zinacantan's Role in Aztec Trade with Soconusco"; y J. P. Viqueira, "Le mythe des colonies préhispaniques au Chiapas central".

"A. Megged, "Accommodation and Resistance of Elites in Transition", p. 488.

${ }^{35}$ B. Díaz del Castillo, Historia verdadera de la conquista de la Nueva España, cap. CLXVI, p. 424. 
quistadores al Altiplano de Chiapas y pusieron a su disposición hasta 300 guerreros para acabar con la resistencia de los insumisos. ${ }^{36}$ Después de derrotar a los chamulas y a los huixtecos, un grupo de zinacantecos acompañó a los españoles a Los Cimatanes, enseñándoles el camino a las Llanuras de Tabasco que pasaba por Tapilula y su desviación al Valle de Huitiupán. ${ }^{37}$ No en vano, Bernal Díaz del Castillo escribió de los indios de Zinacantán "que eran gente de razón $n^{\prime \prime}$. .36

La lealtad de los zinacantecos hacia los españoles continuó manifestándose a todo lo largo del siglo XVI. En 1528, fueron a Jiquipilas a recibir a las tropas de Diego de Mazariegos y a solicitarles su ayuda para recuperar el control sobre el pueblo de Macuil-Suchitepeque, que, aprovechando los cambios que se estaban produciendo, intentaban "independizarse" de Zinacantán. ${ }^{39}$ Luego, construyeron, seguramente junto con los indios de otros pueblos vecinos, las casas y los edificios del asentamiento español en el Valle de Jovel. ${ }^{40}$ Contribuyeron también a someter a los pueblos de Los Zoques que se sublevaron contra el dominio español en 1533 y participaron en la larga y ardua conquista de Los Zendales. ${ }^{41}$ Los alcaldes y "tatoque" de Zinacantán afirmaron en una probanza de méritos que presentaron en 1621 haber colaborado en la conquista de Cuscatlán (Guatemala), San Salvador y Comayagua (Honduras), aunque hasta ahora no se han encontrado otras fuentes que confirmen estas afirmaciones. ${ }^{42}$ En 1559, sirvieron como auxiliares, junto con sus antiguos enemigos los chiapanecas, en la campaña militar contra los lacandones. ${ }^{43}$

En 1545, los dominicos, que acababan de llegar a Chiapas y que se habían enfrentado con los vecinos de Ciudad Real por el problema de los esclavos indios, se trasladaron a Zinacantán y, al año siguiente, construyeron un pequeño convento en el pueblo. ${ }^{44}$ Dando muestras de gran clarividencia y

\footnotetext{
${ }^{36}$ Ibid, cap. CLXVI, pp. 425-427.

${ }^{37}$ D. Godoy, "Relación hecha por ... a Hernando Cortés", p. 467; y A. Megged, "Accommodation and Resistance of Elites in Transition", p. 488.

${ }^{30}$ B. Díaz del Castillo, Historia verdadera de la conquista de la Nueva España, cap. CLXVI, p. 425 .

sy M. H. Ruz, "Una probanza de méritos indígenas, Zinacantán, 1621", p. 348; y G. Lenkersdorf, Génesis histórica de Chiapas, p. 177.

${ }^{40}$ M. H. Ruz, "Una probanza de méritos indigenas, Zinacantán, 1621", p. 349.

41 Ibidern

${ }^{42}$ Ibid, pp. 341-343 y 349.

${ }^{43} \mathrm{Fr}$. A. Remesal, Historia general de las Indias Occidentales ..., libro X, cap. XI, vol. II, pp. 425 426 y cap. XII, vol. II, pp. 429-430.; y J. de Vos, La paz de Dios y del Rey, p. 95.

${ }^{44} \mathrm{Fr}$. A. Remesal, Historia general de las Indias Occidentales ..., libro VI, cap. VI, vol. I, pp. 463 464; y libro VII, cap. XXI, vol. II, pp. 110-111.
} 
perspicacia, los zinacantecos tomaron partido por los frailes predicadores y se mantuvieron invariablemente leales a ellos a pesar de las presiones que recibieron de su encomendero y de las autoridades civiles españolas. ${ }^{15}$ Fue tal el apego de los zinacantecos a los dominicos, que éstos lograron, incluso, encontrar entre ellos a una persona -Bartolomé Tzon, el alguacil del pueblo- dispuesta a colaborar en la erradicación de la poligamia, a pesar de la fortísima resistencia que esta medida producía entre la nobleza india, entre cuyos integrantes esta forma de matrimonio era extremadamente habitual. ${ }^{46}$ Resulta también muy significativo el hecho de que las autoridades eclesiásticas nunca llegaron a tener noticia de prácticas idolátricas en Zinacantán. En efecto, aunque, en 1548, los frailes llevaron a cabo en Zinacantán un gran auto de fe en el que se quemaron muchos ídolos, éstos no provenían del pueblo, sino que habían sido descubiertos en Chiapa, y en distintos lugares de las provincias de Los Zoques y de Los Quelenes. ${ }^{47}$

Es probable que todas estas muestras de lealtad y obediencia hayan contribuido a que los españoles, al llevar a cabo las reducciones de los pueblos de la alcaldía mayor de Chiapas, hayan respetado un poco más la integridad del territorio zinacanteco. En efecto, no hay que olvidar que la política de reducciones impulsada por los dominicos y por las autoridades civiles no buscaba tan sólo acabar con los asentamientos dispersos existentes, sino que pretendía también destruir las unidades político-territoriales prehispánicas, romper las lealtades y las solidaridades "étnicas" o regionales, y confinar a los indios en el estrecho ámbito de sus nuevas "repúblicas".

Sin duda, Zinacantán no estuvo a salvo de esta doble política de congregación de los asentamientos dispersos y de fragmentación de los señoríos, pero en su caso, estas medidas se llevaron a cabo de forma muy peculiar.

\section{Las congregaciones}

Esta originalidad se manifestó sobre todo en el relativo respeto a los lazos que unían ente sí a los indios del señorío de Zinacantán, ya que en lo referente a los asentamientos prehispánicos, éstos —al igual que sucedió con

\footnotetext{
${ }_{45} \mathrm{Fr}$. A. Remesal, Historia general de las Indias Occidentales ..., libro Vl, cap. XXII, vol. I, p. 550; y libro VII, cap. IX y X, vol. II, pp. 49-56; y Fr. F. Ximénez, Historia de la provincia de San Vicente de Chiapa y Guatemala ... (1977), libro II, cap. LVII, pp. 425-431.

${ }^{46} \mathrm{Fr}$. A. Remesal, Historia general de las Indias Occidentales ..., libro VII, cap. XIX, vol. II, pp. 9899; y Fr. F. Ximénez, Ilistoria de la provincia de San Vicente de Chiapa y Guatemala ... (1977), libro II, cap. LX, p. 444.

${ }^{47} \mathrm{Fr}$. A. Remesal, Historia general de las Indias Occidentales ..., libro VIII, cap. XVII, vol. II, p. 208.
} 
la gran mayoría de los de la alcaldía mayor - fueron reubicados y reagrupados- por lo general en lugares abiertos- para formar nuevas poblaciones más compactas y más fácilmente controlables. Así, para fundar la república de indios de Zinacantán se juntaron tres antiguas poblaciones prehispánicas. ${ }^{4 / 3}$ A su vez, la república de Ixtapa nació de la fusión de cinco asentamientos dispersos. ${ }^{49}$ Todo indica que en San Felipe se congregaron los indios que habitaban en el cerro de Ecatepec con algunos de los que se encontraban dispersos en el fondo del valle de Jovel. ${ }^{50}$ Osumacinta y Chicoasén fueron también el resultado del reagrupamiento de diversos asentamientos dispersos de lengua zoque. ${ }^{51}$

Los habitantes de Totolapa, en cambio, abandonaron por iniciativa propia su antiguo poblado para asentarse en tierras que habían pertenecido anteriormente a los chiapanecas, aprovechando que a principios de la década de 1530, éstos se rebelaron en dos ocasiones contra los españoles, retirándose de sus pueblos para concentrarse en lo alto del Cañón del Sumidero. Como parte de esta expansión territorial realizada a expensas de los chiapanecas, otros indios del antiguo señorío de Zinacantán fundaron el pueblo de San Lucas. ${ }^{52}$

\footnotetext{
40 En 1524, en el valle de Zinacantán había tres poblados, que seguramente pasaron a formar parte, tal vez junto a otros, de la nueva república de indios de Zinacantán: D. Godoy, "Relación hecha por ... a Hernando Cortés", p. 465.

${ }^{49} \mathrm{Fr}$. F. Ximénez, Historia de la provincia de San Vicente de Chiapa y Guatemala ... (1977), libro II, cap. IXXIV, p. 515.

"Según, T. A. Lee, "El asentamiento humano precolombino del valle de Hucyzacatlán", es muy probable que el sitio arqueológico de Ecatepec estuviese habitado en el momento de la conquista española.
}

Por otra parte existen varios testimonios de que en el momento de la fundación de villa Real en 1528, habia indios que vivían y tenían sus siembras en el Valle: $H$. López Sánchez, Apuntes históricos de San Cristobal de Las Casas, vol. I, pp. 230-231. Cuando los dominicos erigieron su convento a orillas de Ciudad Real en el año de 1547 consideraron que la principal virtud del sitio elegido era que "está en comarca de los indios del valle, y así finalmente acuden todos alli a misa": Fr. F. Ximénez, Historia de la provincia de San Vicente de Chiapa y Cusatemala ... (1977), libro II, cap. LXIII, pp. 460.

"1 Al menos eso se deduce del hecho de que estos dos pueblos se componian, el primero de. cuatro calpules y el segundo de cinco calpules y dos parcialidades: AGI, Guatemala, 215, exp. 2 (3), ff. 44-45v. Pueblo de Osumacinta. Osumacinta, [1690]; y ff. 45v-46v. Pueblo de Chicoasén. Chicoasén, [1690]; G. Enriquez, "Nuevos documentos para la demografia historica...", p. 151; y "Despoblación de Xiquipilas, Tacoasintepec, Las Pitas ...", p. 62. Una parcialidad de Chicoasén era Estapa, pueblo mencionado por B. Díaz del Castillo, historia verdadera de la conquista de la Nueva España, cap. CLXVI, p. 420

${ }^{52} \mathrm{C}$. Navarrete, The Chiapanec. History and Culture. pp. 99-103; y E. E. Calnek, "Los pueblos indigenas de las tierras altas", p. 126. El pueblo de San I ucas aparece mencionado en forma 
Los habitantes de otros asentamientos fueron trasladados fuera del territorio que había pertenecido al señorío de Zinacantán y reagrupados junto con indios de otras unidades políticas prehispánicas. Amaitic, que al parecer se encontraba en la Meseta de Ixtapa, ${ }^{53}$ fue reubicado unos 40 kilómetros más al este, en las tierras frías del Macizo Central, sin duda con el objetivo de acercar a sus habitantes un poco más a Ciudad Real y así obligarlos a prestar "servicios personales" a los españoles de la sede de la alcaldía mayor. Pero a fines del siglo XVI, los indios de Amaitic solicitaron ser trasladados a otro lugar, ya que se estaban "consumiendo y acabando en el sitio donde ahora están por ser malo y enfermo $0^{1.54}$ Las autoridades accedieron finalmente a su demanda y les permitieron mudarse al pueblo de Simojovel, en el fondo del Valle de Huitiupán. ${ }^{55}$

El pueblo de Quetzaltenango del señorío de Zinacantán bien podría ser el mismo que el que en ciertos documentos aparece bajo el nombre de Quetzaltepec. En los años de 1532, los indios de Quetzaltepec se rebelaron contra los españoles y se refugiaron en un peñón, desde el cual ofrecieron una encarnizada resistencia. ${ }^{56}$ Tras su derrota, fueron congregados en el pueblo de Aguacatenango, de lengua tzeltal, dando lugar a la parcialidad del mismo nombre. ${ }^{57}$

En cambio, ignoramos el destino de los habitantes de MacuilSuchitepeque que tras la primera incursión española se habían sublevado contra los zinacantecos con el fin de recobrar su indeperdencia.

muy irregular en los documentos del siglo XVII que enlistan los pueblos de Chiapas, tal vez porque era a veces considerado como una "estanzuela" de Zinacantán (AGI, Escribanía, 356 A, exp. 1 (1), ff, 223-223v. Declaración de los indios vecinos y naturales del pueblo de San Lucas, estanzuela de Zinacantán, Priorato de Chiapa. Ciudad Real, 25 de noviembre 1719.) o incluso como un ibarrio de Ciudad Real! (AHDSC, exp. 28, ff. 10-12. Carta del señor obispo al señor presidente de Guatemala. Ciudad Real, 20 de julio 1659). Sin embargo, lo más seguro es que su poblamiento haya sido continuo.

53 E. Calnek, "Los pucblos indígenas de las tierras altas", pp. 126-127, afirma que Amaitic (o Acatepec, en náhuatl) era un sujeto de Zinacantán que se encontraba por el rumbo de San Gabriel o Soyaló, desgraciadamente no proporciona las fuentes en que basa esta afirmación.

${ }^{54} \mathrm{~L}$. Reyes Garcia, "Movimientos demográficos en la población indigena de Chiapas durante la época colonial", p. 31.

"E. Calnek, "Los pueblos indígenas de las tierras altas", pp. 126-127.

3. J. de Vos, La batalla del Sumidero, pp. 145-146; y G. Lenkersdorf, Génesis histórica de Chiapas, pp. 208-209.

${ }^{57} \mathrm{ACl}$, Guatemala, 33, exp. 3, [ff. 4v-5]. Certificación de haberse recibido diferentes tasaciones. Ciudad Real, 21 de septiembre 1690; y 75, $\exp , 4$ (1), [ff. 1v-2v]. Memoria de los pueblos. [Guatemala, marzo 1679]. 


\section{La desintegración del señorío de Zinacantán}

Aunque en principio las repúblicas de indios eran totalmente independientes unas de otras - cada una de ellas tenía su cabildo y pagaba sus tributos-, los españoles no buscaron romper de tajo las relaciones que habían existido entre los habitantes del señorío de Zinacantán y las tomaron en cuenta a la hora de erigir el nuevo orden colonial.

Para empezar, no hay que olvidar que los españoles eran conscientes de que las identidades y las lealtades prehispánicas basadas en las antiguas unidades político-territoriales no podían desaparecer de un día para otro, de que no se podía hacer tabla rasa del pasado, y que por lo menos en un primer momento había que seguir tomándolas en cuenta. Un caso muy significativo de la supervivencia de las viejas solidaridades en el marco de las nuevas repúblicas de indios tuvo lugar en 1571. Ese año, se entabló ante las autoridades españoles un pleito entre indios por la posesión de unas tierras ubicadas entre Chiapilla y Totolapa. Su originalidad radica en que el juicio no se presentó como una reclamación de los habitantes de Chiapilla contra los de Totolapa, como sería lógico suponer dentro del nuevo orden colonial. Por el contrario, los demandantes fueron los indios de Chiapa y los acusados, los habitantes de Zinacantán, San Felipe e Ixtapa. Además estas reclamaciones se mezclan, con sorprendente naturalidad, con la añeja disputa entre Chiapa e Ixtapa por el control de las salinas. ${ }^{5 B}$ Es decir que detrás de los nombres de las nuevas repúblicas de indios se encuentran en realidad los antiguos señoríos prehispánicos de Chiapa y Zinacantán, cuya rivalidad ancestral se mantenía viva.

Pero más allá de estas identidades colectivas que se resistían a desaparecer a pesar de las profundas transformaciones impuestas por el nucvo orden colonial, los españoles reactualizaron algunos de los lazos que existían entre gran parte de los habitantes del señorío de Zinacantán, dándoles cabida en las nuevas instituciones que se estaban creando.

Así, por ejemplo, durante todo el siglo XVI, Ixtapa fue considerado casi siempre como un simple anexo de Zinacantán..$^{59}$ Solamente a principios del siglo siguiente, Ixtapa fue reconocido totalmente como una república de indios independiente, lo que supuso un debilitamiento de las relaciones que

\footnotetext{
×. Navarrete, The Chiapanec. History and Culture. pp. 99-103.

$59 \mathrm{Fr}$. F. Ximénez, Historia de la provincia de San Vicente de Chiapa y Guatemala ... (1977), libro II, cap. XLIV, p. 376.

En el censo de tributarios que el obispo fray Andrés de Ubilla envió a España en 1595, no aparece en pueblo de Ixtapa, seguramente porque se le consideraba parte de Zinacantán: AGI,
} 
tenía con su antigua cabecera. ${ }^{\text {60 }}$ En cambio, el pueblo de San Lucas siguió siendo considerado hasta principios del siglo XVIII como una simple estanzuela de Zinacantán ${ }^{61}$.

Pero el caso más sorprendente es sin duda cl de la encomienda de Zinacantán: Una de las principales formas en que la Corona recompensó a los conquistadores y a los funcionarios coloniales fue dándoles en encomienda determinados asentamientos prehispánicos, que quedaban obligados a entregarles como tributo diversos productos y trabajo. Dado que el primer reparto de encomiendas se llevó a cabo antes de que se realizaran las congregaciones, no tiene nada de sorprendente que éste se realizara en función de las unidades político-territoriales anteriores a la conquista. Ello permitía utilizar los mecanismos prehispánicos de recaudación del tributo en provecho de los encomenderos y de la Corona española. El corolario de esta política era el mantener gran parte de los privilegios de la aristocracia india, de los llamados "caciques" o "señores de la tierra". Aunque ciertamente los favorecidos por los españoles no siempre fueron los antiguos dirigentes o sus descendientes, sino que en ocasiones su lugar fue ocupado por oportunistas que destacaron por su lealtad a los conquistadores. Estos "señores" servían entre otras cosas de intermediarios entre la sociedad india y el mundo español.

La encomienda de Zinacantán abarcó en un principio los asentamientos que luego habrían de fundirse en las repúblicas de indios de Osumacinta, Chicoasén, Amaitic, Ixtapa, Zinacantán, San Felipe, San Lucas, y Río de Cedros [¿Totolapa?], es decir todo el antiguo señorío de Zinacantán, con la excepción de los pueblos tzeltales de Macuil-Suchitepeque y Quetzaltenango.

A principios del siglo XVII, cuando la Corona española optó por reducir el poder de los encomenderos, dividiendo las encomiendas originales, en el caso de la de Zinacantán se recurrió a un procedimiento muy original. En vez de asignar los distintos pueblos que la componían a varios encomenderos,

Guatemala, 161, exp. 13 (2), 2 ff. Memoria de los pueblos y beneficios que hay en el obispado de Chiapas y lo que tienen los clérigos $y$ frailes. [1595].

to La primera mención que hemos encontrado de Ixtapa cómo pueblo independiente de Zinacantán es de 1611: AGl, México, 3102, exp. 1, ff. 40-47. [Informe de don Fructus Gómez, deán de la catedral de Chiapas]. Ciudad Real, 1 de octubre 1611.

t1 AGl, Escribanía, 356 A, exp. 1 (1), f. 223-223v. Declaración de los indios vecinos y naturales del pucblo de San Lucas, estanzuela de Zinacantán, Priorato de Chiapa. Ciudad Real, 25 de noviembre 1719.

Señalemos que esta división entre pueblos cabecera y pueblos sujetos, a pesar de ser muy frecuente durante la época colonial en otras regiones de Mesoamérica, era totalmente excepcional en Chiapas. 
se mantuvo la encomienda en su forma original, pero su "poseedor" recibiría solamente un porcentaje del tributo. El resto se repartiría entre los demás beneficiarios. De esta forma, los mecanismos de recolección del tributo de origen prehispánico se mantuvieron vigentes todavía varias décadas más, ahora bajo el control de los oficiales reales. ${ }^{62}$

De la misma manera, los dominicos, al dividir en parroquias los territorios que administraban, respetaron parcialmente los límites del antiguo señorío de Zinacantán, aunque para facilitar el trabajo del fraile a su cargo lo amputaron de los pueblos en los que se hablaba una lengua distinta del tzotzil. Así la primitiva parroquia de Zinacantán incluía los pueblos de Zinacantán, Ixtapa, San Felipe, Totolapa, y muy probablemente también el de San Lucas. ${ }^{6.3}$ Sin embargo en 1577, obedeciendo órdenes del obispo fray Pedro de Feria, los dominicos tuvieron que ceder el pueblo de San Felipe a los franciscanos que acababan de llegar a Chiapas. ${ }^{64}$ Con ello la continuidad geográfica de la primera parroquia de Zinacantán desapareció. Lógicamente en 1659, cuando se procedió a una nueva división de los pueblos a cargo de los dominicos, San Lucas y Totolapa quedaron integrados a la parroquia dominica de Ciudad Real. La de Zinacantán se redujo, entonces, a la cabecera y a tres anexos que eran Ixtapa y dos pequeñas poblaciones de reciente creación, San Gabriel y Soyaló. ${ }^{65}$

En el año de 1690, se produjo un cambio fundamental en la organización de esta parroquia: Los dominicos trasladaron la cabecera de Zinacantán a Ixtapa. ${ }^{66}$ Esta decisión se explica en buena medida por las divergentes evoluciones demográficas y comerciales que ambos pueblos habían conocido tras la conquista española.

En efecto, Zinacantán padeció con especial intensidad las epidemias que diezmaron a los indios de Chiapas durante los siglos XVI y XVII. En 1565, se desató una epidemia de peste que afectó sobre todo a las mujeres, a los niños y a los mancebos, comprometiendo así muy seriamente las posibilidades de recuperación de la población durante varias décadas. ${ }^{67} \mathrm{~A}$ consecuencia ${ }^{62}$ AGI, Escribanía, 334 B, exp. 1, 279 ff.

${ }^{6}$ ]. de Vos, Fray Pedro Lorenzo de la Nada, p. 85; y Fr. F. Ximénez, Historia de la provincia de San Vicente de Chiapa y Guatemala ... (1930), libro IV, cap. XVIII, pp. 63-64.

${ }^{64}$ M. H. Ruz, Chiapas colonial: Dos esbozos documentalcs, p. 42.

65 AHDSC, exp. 28, ff. 10-12. Carta del señor obispo al señor presidente de Guatemala. Ciudad Real, 20 de julio 1659.

66 AHDSC, exp. 30, Libro de registro (1683-1730), f. $110 \mathrm{v}$ (11 de octubre 1689 ); y AGi, Guatemala, 215, exp. 2 (3), if. 89-90. Ixtapa, cabccera de curato. Ixtapa, [1690]; y ff. 91-92. Pueblo de Zinacantán, de la dicha doctrina. Zinacantán, [1690].

${ }^{67} \mathrm{Fr}$. A. Remesal, Historia general de las Indias Occidentales ..., libro X, cap. XVIII, vol. II, pp. 471. 472 . 
de ello, Ixtapa se convirtió desde 1605 en el asentamiento más grande de la parroquia. ${ }^{\text {6a }}$

Aunque Zinacantán creció ligeramente durante la primera mitad del siglo XVII, entre 1650 y 1665 volvió a sufrir una importante caída demográfica. $^{69}$ Una vez más Ixtapa logró salir mejor librado de esta nueva catástrofe. Es probable que el hecho de que Ixtapa, a diferencia de Zinacantán, hubiese logrado ser liberado de la obligación de trabajar en las obras públicas de Ciudad Real haya profundizando las diferentes evoluciones demográficas entre ambos pueblos. ${ }^{70}$

Por otra parte, los españoles mantuvieron abierto parte del camino prehispánico controlado por los zinacantecos. Esto contribuyó a mantener las relaciones existentes entre los pueblos de la parte occidental del antiguo señorío, aunque al mismo tiempo debilitó a Zinacantán frente a Ixtapa. En efecto, al desaparecer la lucha abierta entre chiapanecas y zinacantecos como resultado de la "pax hispana", el desvío entre Copanaguastla y Osumacinta por Los Altos de Chiapas para evitar las exacciones de los chiapanecas dejó de. tener sentido. Sin embargo, la fundación de Ciudad Real en el Valle de Jovel activó los intercambios de esa región con Chiapa, con México y con Tabasco, aprovechando parte del camino zinacanteco. Con la modificación de las rutas comerciales, Ixtapa quedó ubicado en el cruce de dos importantes caminos. Uno de ellos, era el que comunicaba a los habitantes de Ciudad Real con el puerto fluvial de Quechula y de ahí con las llanuras del Golfo de México y con el Altiplano de México. El otro camino era el que unía Chiapa de Indios (que durante los siglos XVI y XVII fue el asentamiento más grande y más dinámico de toda la alcaldía mayor) con Tabasco a través de la meseta de Ixtapa, los valles de Jitotol y el valle del río Teapa. ${ }^{n}$

Las haciendas españolas hicieron entonces una discreta aparición en la región de la meseta de Ixtapa en el siglo XVII y principios del XVIII, con el fin

t.s AGl, México, 3102, exp. 1, ff. 40-47. [Informe de don Fructus Gómez, deán de la catedral de Chiapas]. Ciudad Real, 1 de octubre 1611.

${ }^{69}$ AGCA, Guatemala, A.3.2, leg. 825, exp. 15207; AGl, Contaduría, 815, exp. 1, ff. 11v-16v. [Relación de las ciudades, barrios y pueblos, vecinos y tributarios de Chiapas]. Ciudad Real, 20 de mayo 1683; G. Enriquez, "Nuevos documentos para la demografia histórica...", pp. 147. 155. En J. P. Viqueira, Indios rebeldes e idólatras, pp. 165-180, se hace un análisis crítico de estas fuentes con el fin de fechar con la mayor exactitud los datos que contienen.

${ }^{70} \mathrm{M}$. H. Ruz, "Una probanza de méritos indiggenas, Zinacantán, 1621 ", pp. 345, 349, y 358 361.

"C. Navarrete, "El sistema prehispánico de comunicaciones entre Chiapas y Tabasco"; y T. A. Lee, "las rutas históricas de Tabasco y el norte de Chiapas". 
de abastecer a los viajeros y proporcionarles animales de carga. ${ }^{72}$ Este desarrollo comercial de Ixtapa explica también la fundación de los pueblos de San Gabriel y Soyaló, ambos ubicados en los extremos de la Meseta. Estos pueblos son mencionados por primera vez a mediados del siglo XVII. En los dos casos se trata de pequeños establecimientos (que tenían entre 12 y 45 tributarios) que servían de puestos de descanso para los viajeros. ${ }^{73}$

La creciente importancia de Ixtapa no pudo más que despertar resentimientos entre los zinacantecos, resentimientos que sin duda ayudan a entender la actitud de éstos ante la rebelión de 1712 que se inició en el pueblo de Cancuc.

\section{La rebelión de 1712}

A principios del mes de agosto de 1712, estalló en la alcaldía mayor de Chiapas una de las rebeliones indias más importantes que haya conocido el Reino de Guatemala. Las provincias de Los Zendales, Coronas y Chinampas, y Guardianía de Huitiupán - cuya población representaba casi $40 \%$ del total de la alcaldía - se levantaron en armas con el propósito declarado de acabar con el dominio español, cuando una joven india de Cancuc, María de la Candelaria, declaró que la Virgen se le aparecía y le decía que había que matar a todos los españoles, incluyendo a los frailes y clérigos. ${ }^{74}$

El 12 y el 14 de agosto respectivamente, los rebeldes atacaron y tomaron Chilón y Ocosingo, poblados en los que se habían concentrado los pocos españoles de la parte noreste de la alcaldía mayor. Con estas acciones los rebeldes lograron el control de todos los pueblos de Los Zendales y de la Guardianía de Huitiupán, con las únicas excepciones de Simojovel y Los Plátanos. Los españoles de Ciudad Real intentaron contraatacar, pero el día 25 fueron sitiados en Huixtán. Solamente la llegada de refuerzos, compuestos principalmente por indios del pueblo de Chiapa que se mantuvieron leales a la Corona, los salvó de una inminente derrota.

\footnotetext{
72 «Escritura de venta del sitio El Burrero (1651)w, pp. 15-20. Es muy probable que, dado su nombre, la hacienda de El Burrero, ubicada a mitad camino entre Zinacantán e Ixtapa, se dedicara principalmente a la cría de burros.

En 1774, el obispo M. García Vargas y Rivera, Relaciones de los pueblos del obispado de Chiapas, p. 20, menciona la existencia de la hacienda de San Nicolás al sur de Ixtapa. El obispo Polanco menciona en 1777 las de San Nicolás, Cacaté, Alchitón y El Burrero: AGl, Guatemala, 949, exp. 2 (b), ff. $6 \mathrm{v}-8 \mathrm{v} .3$ IVisita de la parroquia de Ixtapa]. 21-23 de diciembre 1777.

${ }^{73}$ AGCA, Guatemala, A.3.2, leg. 825, exp. 15207.

${ }^{74} \mathrm{La}$ relación más detallada de esta rebelión sigue siendo la de Fr. Gabriel de Artiga incluido en Fr. F. Ximénez, Historia de la provincia de San Vicente de Chiapa y Guatemala ... (1971), libro VI, cap. 57-76, pp. 249-358.
} 
Después de esta batalla, los españoles ju<garon más prudente atrincherarse en Ciudad Real y pedir ayuda a Guatemala y Tabasco. Así, durante casi tres meses, los rebeldes tuvieron tiempo para esbozar un nuevo orden social en la amplia región que quedó bajó su control y que se componía de las provincias de Los Zendales y de Guardianía de Huitiupán, a los que se sumaron entonces parte de la de Coronas y Chinampas, quedando así incluidos en ella pueblos de habla tzeltal, tzotzil y chol.

Sin embargo, esta gran república india no resistió los embates de las tropas numerosas y bien pertrechadas que llegaron de Guatemala, al mando del presidente de la Audiencia, don Toribio de Cosío. Derrotados primero en Oxchuc, los rebeldes intentaron resistir en Cancuc, aprovechando su ubicación en lo alto de un monte rodeado de profundas barrancas, pero, el 21 de noviembre, fucron vencidos por los pedreros y fusiles de los atacantes. Los pueblos más cercanos se rindieron entonces, mientras que los habitantes del norte de Los Zendales siguieron ofreciendo cierta resistencia, refugiándose en las montańas. Aunque los españoles no tuvieron que librar más batallas, la tarea de sacar a los indios de los montes y de reducirlos a sus poblados les llevó varios meses de arduo trabajo.

Cuando esta rebelión estalló, los zinacantecos dudaron qué actitud tomar ante los acontecimientos. Estaban dispuestos a unirse a la rebelión siempre y cuando ésta tuviese verdaderas probabilidades de triunfar. Pero si de lo que se trataba era de lanzarse a una aventura suicida, consideraban preferible mantenerse al margen. El problema radicaba justamente en vislumbrar ante cuál de los dos casos se encontraban. Cuando los españoles salieron rumbo a Huixtán, los zinacantecos pensaron que se encaminaban a una derrota segura y se prepararon, con prudencia, a pasarse al campo rebelde. Apresaron a los correos que cruzaban por su pueblo y a un español, propietario de una labor cercana, Juan de Peña, al que sorprendentemente le ofrecieron que fuera su capitán. ${ }^{75}$ Pero apenas llegó a sus oídos el desenlace del enfrentamiento en Huixtán soltaron a los reos, y acudieron con el padre doctrinero para decirle que sólo se había tratado de un malentendido. Los españoles, que necesitaban que el camino real con Chiapa y la Audiencia de México estuviera abierto, se hicieron en un primer momento de la vista gorda. ${ }^{76}$

\footnotetext{
$75 \mathrm{AGl}$, Guatemala, 293, exp. 3, ff. 17v-23v. [Carta de don Sebastián de Olivera Ponçe de Lcón]. [Ciudad Real, fines de agosto o septiembre 1712].

${ }^{76}$ AGi, Guatemala, 295, exp. 5, ff. 67v-74v. Carla [de Pedro Gutiérrez a Toribio de Cosio]. Ciudad Real, 22 de septiembre 1712.
} 
Más adelante, ante la pasividad de Ciudad Real, los zinacantecos volvieron a dudar. Uno de sus alcaldes se dirigió entonces a Chalchihuitán a hacer - dijo- unas diligencias. ${ }^{77}$ Probablemente iba a sondear a los habitantes de las Montañas Chamulas sobre su actitud ante la rebelión. Después de esta visita, los zinacantecos se mostraron remisos y altaneros. A mediados de septiembre las justicias se rehusaron a darle montura a un correo que iba a Tabasco a pedir pedreros. Esta desobediencia les costó a los alcaldes y regidores el ser condenados a muerte por el alcalde mayor de Chiapas. ${ }^{78}$ Después de lo cual el común se mantuvo en paz, tan sólo algo compungido por haber mancillado su fama de leales defensores de las dos majestades. ${ }^{79}$

\section{La desaparición del señorío de Zinacantán}

En cambio, el resto del antiguo territorio del señorío de Zinacantán se mantuvo totalmente leal a los españoles durante toda la rebelión. Las dudas y la ambigüedad de Zinacantán contribuyeron entonces a profundizar las diferencias cada vez más evidentes entre este pueblo y todos los otros que habían estado bajo su sujeción. A mediados del siglo XVIII, el pucblo de Zinacantán fue separado de la parroquia de Ixtapa, que quedó limitada a la cabecera, San Gabriel y Soyaló. ${ }^{80}$ Esta división marcó el punto final del lento desmembramiento del territorio prehispánico de los zinacantecos, iniciado con la conquista española.

Desde ese momento, la república de indios de Zinacantán empezó a evolucionar de manera radicalmente opuesta al resto de los pucblos del antiguo señorío. En efecto, a partir de esas fechas, las haciendas españolas se extendieron en la Meseta de Ixtapa. En cambio, Zinacantán logró mantener con un poco más de éxito la integridad de sus tierras.

Por otra parte, las tendencia demográficas de los dos pueblos volvicron a invertirse: Mientras que ixtapa entró en un proceso de franco estancamiento, Zinacantán vio su población multiplicarse aceleradamente durante todo el siglo XVIII. ${ }^{81}$ Los zinacantecos tuvieron entonces que buscar tierras

\footnotetext{
${ }^{7}$ AGl, Guatemala, 296, exp. 9, ff. 177v-181. Declaración de Mateo Pérez de 35 años. Ciudad Real, 3 de octubre 1712.

75 AGl, Guatemala, 295, exp. 5, ff. 67v-74v. Carta [de Pedro Gutiérrez a Ioribio de Cosío]. Ciudad Real, 22 de septiembre 1712; y 296, exp. 9, ff. 116-120. Auto [de. Pedro Gutiérrez]. Ciudad Real, 18 de septiembre 1712 .

79 AGi, Guatemala, 296, exp. 9, ff. 183v-185v. Carta [de fray José Monroy a Pedro Gutiérrez]. Chamula, 3 de octubre 1712 .

${ }^{m}$ M. García Vargas y Rivera, Relaciones de los pueblos del obispado de Chiapas, p. 7.

81 AHDSC, exp. 19. [Año de 1778. Borrador del censo de 1778 del obispo Francisco Polanco]. [Anotación actual: Padrones s.f. 1778].
} 
que cultivar en lugares cada vez más alejados de su pueblo. En 1819, su cura afirmó que casi todos los indios a su cargo tenían una casa en el pueblo y otra en su milpa. ${ }^{82}$ En el siglo XIX, muchos indios fueron abandonando la cabecera para instalarse en forma permanente más cerca de sus tierras, formando rancherías habitadas por unidades domésticas generalmente emparentadas entre sí. Este proceso fue el que dio nacimiento a los actuales parajes, que muchos antropólogos insisten en considerar en forma simplista como una continuación mecánica de las formas de poblamiento disperso de la época prehispánica.

Pero el fenómeno más importante que se produjo durante el siglo XIX y principios del XX fue la acelerada ladinización de todo el antiguo scñorío con la única excepción del municipio de Zinacantán. Para los años de 1950, en Totolapa, San Lucas, San Felipe, Ixtapa, Soyaló, San Gabriel (rebautizado como El Palmar), Osumacinta y Chicoasén, sólo un porcentaje muy reducido de sus pobladores continuaba hablando alguna lengua mesoamericana. ${ }^{A 3}$ Además prácticamente todos ellos habían abandonado los rasgos culturales que se consideraban más característicos de los indios (como el uso de una vestimenta propia). Este proceso no se debió tanto a un progresivo mestizaje con habitantes venidos de otros lugares, sino que fue más bien el resultado del abandono de las viejas formas de identidad india con el fin de entablar relaciones menos desiguales con el resto de la sociedad chiapaneca. En cambio, los zinacantecos optaron por conservar hasta nuestros días su identidad india, acercándose así a los demás pueblos de Los Altos de Chiapas, que nunca habían formado parte de su antiguo territorio.

A mediados de nuestro siglo, Zinacantán y sus parajes habían roto prácticamente todos los lazos que los unían al resto de los pueblos del antiguo señorío y habían adquirido una personalidad propia basada en su lengua, el tzotzil, en el uso de una vestimenta original, y en la existencia de cargos políticos y religiosos que aseguraban la dependencia de los parajes con respecto a la cabecera, rasgos todos ellos que contribuían a mantener una identidad localista muy arraigada. Finalmente, en el ańo de 1951, se inauguró el tramo de la carretera panamericana que conecta Chiapa de Corzo con San Cristóbal de Las Casas (antes Ciudad Real) y que sigue un trazo diferente al del vicjo camino prehispánico y colonial. Así aunque la carretera cruza por el municipio de Zinacantán, ya no lo hace por la cabecera. A partir de ese mo-

\footnotetext{
"L. Reyes García, "Movimientos demográficos en la población indígena de Chiapas durante la época colonial", p. 45.

"i Séptimo censo general de población, 6 de junio de 1950. Estado de Chiapas.
} 
mento, el pueblo de Zinacantán quedó fuera de los circuitos comerciales de Chiapas. El escenario estaba puesto para que a la llegada de los primeros antropólogos norteamericanos a Chiapas, éstos pudieran descubrir a un grupo indigena aislado que había logrado conservar intactas sus formas de vida y sus creencias por más de cinco siglos. La idea de que la identidad misma de ese grupo era el resultado de un largo proceso de cambio que sc había iniciado en el momento de la Conquista espan̆ola, no les pasó ni siquiera por la cabeza.

Hoy en día, sólo ciertas prácticas aisladas — como la costumbre de los zinacantecos de ir a comprar sal a Ixtapa para revenderla en San Cristóbal de Las Casas- atestiguan la estrecha relación que unió durante siglos estos dos asentamientos. ${ }^{84}$ De la antigua grandeza del señorío de Zinacantán no queda ni siquiera el recuerdo. ${ }^{85}$ La inquebrantable lealtad de los zinacantecos hacia los españoles había servido solamente para retrasar la desintegración del extenso territorio que había tenido bajo su control.

\section{Reflexiones finales}

Son muchas las enseñanzas que se pueden derivar de este esfuerzo por mostrar el carácter histórico de las identidades indígenas del estado de Chiapas y por reconstruir, necesariamente en forma fragmentaria, las etapas de la formación del actual territorio de Zinacantán. Señalemos aquí tan sólo dos de las más evidentes: Los análisis antropológicos no pueden prescindir de la dimensión histórica, ni sustituir la larga, y a menudo infructuosa, búsqueda de documentos históricos y el cuidadoso análisis de éstos por vagas especulaciones en las que se "deduce" toda la evolución histórica de un grupo humano a partir de la confrontación de sus rasgos actuales con aquellos que se suponen fueron los suyos antes de la intrusión de la cultura occidental.

En segundo lugar, los estudios sobre procesos de cambio y continuidad cultural no pueden ceńirse de ninguna manera a los estrechos límites de la comunidad como ha sido el caso de innumerables investigaciones

\footnotetext{
${ }^{84}$ El Dr. Robert M. Laughlin, tras leer el manuscrito de este artículo, me ha señalado, muy amablemente, otras costumbres zinacantecas que muy probablemente se derivan de las estrechas relaciones que Zinacantán guardó con Ixtapa, San Lucas y Totolapa. Desgraciadamente no me ha sido posible integrar las informaciones que me proporcionó a este trabajo.

"ss La actual división municipal ha oscurecido todavia más la unidad pasada del señorío de Zinacantán, ya que mientras que San Lucas, Totolapa, Zinacantán, Ixtapa, Soyaló, Osumacinta y Chicoasén son las cabeceras de otros tantos municipios del mismo nombre, San Gabriel ahora denominado El Palmar - forma parte del municipio de Chiapa de Corzo y San Felipe está incluido en el de San Cristóbal de Las Casas.
} 
antropológicas. La comunidad no es un sujeto colectivo intemporal que lucha contra el mundo exterior por preservar su ser y mantener su cohesión a través de mecanismos de redistribución de la riqueza, sino una creación histórica, en constante transformación, que es el resultado de proyectos humanos encontrados, muchos de los cuales tienen su origen a cientos o miles de kilómetros de distancia. Ninguna investigación debería olvidar que hoy en día toda realidad humana es el producto de un complejo entrelazamiento de fucrzas locales, regionales, nacionales y mundiales.

\section{Documentos utilizados}

\section{Archivo General de Centroamérica (AGCA), Guatemala, Guatemala} ACCA, Guatemala, A.3.2, leg. 82.5. ?

AGCA, Guatemala, A.3.2, leg. 825, exp. 15207. [Padrón de tributarios de la provincia de Guatemala y San Vicente de Chiapas]. [21 ff.]

\section{Archivo General de Indias (AGI), Sevilla, España.}

AGl, Contaduría, 815. Relación de los ramos de la Real Hacienda, valores de clla, cargas y obligaciones: noticias tocantes a la población: tribunales, ministros y empleados, así en todo el reino, como en las islas Filipinas: desde 1682 a 1754 .

AGI, Contaduría, 815, exp. 1. Guatemala,[1683-1684]. Razón de las ciudades, villas y lugares, vecindarios y tributarios de que se componen las provincias del distrito de esta Audiencia [186 ff.].

AGI, Escribanía, 334 B. Guatemala. Pleitos 4 (B).

AGl, Escribanía, 334 B, exp. 1. Guatemala, año de 1629. Pedro Arnáe 2 de Solórzano, como padre legítimo, administrador de su hijo Melchor Solórzano contra Melchor Solórzano, su hermano, vecinos de la Ciudad Real de Chiapas, sobre la encomicnda de indios de los pueblos de lxtapa, Santo Domingo Zinacantán y otros que tuvo su padre, Melchor Solórzano. Legajo $4^{\circ}$ de pleitos de Guatemala [279 ff.].

AGI, Escribanía, 356 A. Residencias de Guatemala, 13 (A).

AGl, Escribanía, 356 A, exp. 1 (1). Año de 1719. Autos de residencia que, con comisión de los señores presidente y oidores de la Real Audiencia de Guatemala, sindicó el secretario Pedro Pereira, escribano de cámara, propietario de dicha Real Audiencia, mayor de gobierno y guerra en las provincias de este reino, al sargento mayor don Pedro Gutiérrez de Mier y Terán, caballero del orden de Santiago, del tiempo que fue alcalde mayor y teniente de capitán general de la provincia de Chiapas, y a sus 
tenientes y ministros, y al cabildo, justicia y regimiento, y demás oficiales de república que en dicho tiempo lo fueron. Acumulose a esta residencia, testimonio de la información reservada sobre averiguar los fraudes cometidos por los alcaldes mayores en los remates de maíces, chile $y$ frijol que pagan los indios por sus tributos [442 ff.].

AGI, Guatemala, 161. Cartas y expedientes de los obispos de Chiapas. 15411699.

AGI, Guatemala, 161, exp. 13 (2). [1598]. Memoria de los pueblos y beneficios que hay en el obispado de Chiapas y lo que tienen los clérigos [2 ff.].

AGI, Guatemala, 215. Cartas y expedientes del presidente y oidores de aquella Audiencia. Años de 1653 a 1699.

AGl, Guatemala, 215, exp. 2 (3). [1690. Testimonio de la primera y segunda pregunta de la visita general de Scals a la provincia de Chiapas I [97 ff.]. AGI, Guatemala, 293. Expediente sobre la sublevación y pacificación de 32 pueblos de la provincia de Chiapas. Años de 1712-1721.

AGI, Guatemala, 293, exp. 3. Año de 1712. No. 21. Testimonio del segundo cuaderno de autos hechos a razón de las noticias recibidas, participadas de la provincia de Chiapas, de mantenerse en su rebeldía los indios de los pueblos del partido de Los Zendales sublevados y en razón de las providencias que se han dado para su pacificación o castigo [39ff.].

AGI, Guatemala, 295. Expediente sobre la sublevación y pacificación de 32 pueblos de la provincia de Chiapas. Años de 1712 a 1721. Legajo $3^{\circ}$.

AGI, Guatemala, 295, exp. 5. Guatemala, años de 1712 y $1713.8^{\circ}$ cuaderno.

Testimonio de los autos y providencias que se dieron por el señor don Toribio de Cosío, caballero del orden de Calatrava, gobernador y capitán general del reino de Guatemala, y presidente de su Real Audiencia, desde las primeras noticias que se le participaron de la sublevación de los pueblos de indios del partido de Los Zendales en la provincia de Chiapas, hasta que su señoría salió de dicha ciudad de Guatemala a entender en su pacificación y lo que en su ausencia se actuó en dicha ciudad de Guatemala por su teniente de gobernador y capitán general [214 ff.].

AGI, Guatemala, 296. Expediente sobre la sublevación y pacificación de 32 pueblos de la provincia de Chiapas. Años de 1712 a 1721. Legajo $4^{\circ} \mathrm{y}$ último.

AGl, Guatemala, 296, exp. 9. Ciudad Real, año de 1712. Cuaderno $7^{\circ}$ Testimonios de los autos que se hicieron por la justicia ordinaria y alcalde mayor de Chiapas desde que comenzó la sublevación de los treinta y 
dos pucblos de los partidos de Los Zendales, Coronas, Chinampas y Guardianía de Huitiupán, hasta que llegó a Ciudad Real a entender personalmente en su pacificación el señor don Toribio de Cosío...[272ff.]. AGI, Guatemala, 33. Cartas y expedientes del presidente y oidores de la Audiencia de Guatemala. 1691.

AGI, Guatemala, 33, exp. 3. Guatemala, 19 de diciembre 1691. A su majestad. Fl oidor don José de Scals remite el testimonio adjunto de que pidió en aquella Audiencia se le diese la ayuda de costa que disponen las leyes por la visita que hizo de la provincia de Chiapas sólo se le mandó hacer bueno a razón de 200000 maravedís al año sobre que representó lo que se le ofrece suplicando se mande se le den 1500 pesos que son los mismos que está debiendo y causa de empeño en el viaje. [Carta: 1 f.; Testimonio: $6 \mathrm{ff}$.]

AGI, Guatemala, 75. Cartas y expedientes de personas seculares del distrito de dicha Audiencia, vistos en el Consejo. Años de 1682 a 1686.

AGl, Guatemala, 75, exp. 4 (1). [Guatemala, 1679. Testimonio de autos sobre la necesidad que hay de contar los pueblos de Chiapas]. [11 ff.]

AGI, Guatemala, 949. Guatemala, № 28. Expediente del obispo de Chiapas sobre la visita de su Iglesia catedral, la de su diócesis y cuentas de la misma iglesia dadas por su cabildo. Año de 1784.

AGl, Guatemala, 949, exp. 2 (b). No 6 [1778. Visita general del obispo Francisco Polanco a las parroquias de Coronas y Chinampas, Ciudad Real y alrededores, Priorato de Chiapa y Valle de Jiquipilas; Los Llanos y la parroquia de Oxchuc] [34 ff.].

AGI, México, 3102. 1774. Yucatán. Expediente sobre la agregación de la provincia de Tabasco en el obispado de Yucatán a la de Ciudad Real de Chiapas. AGI, México, 3102, exp. 1. Número 11. Primera pieza con 154 fojas [del expediente sobre la agregación de la provincia de Tabasco en el obispado de Yucatán a la de Ciudad Real de Chiapas] [154 ff.].

Archivo Histórico Diocesano de San Cristóbal (AHDSC), San Cristóbal de Las Casas, México

AHUSC, exp. 19. [Año de 1778. Borrador del censo de 1778 del obispo trancisco Polanco]. [Anotación actual: Padrones s.f. 1778].

AHDSC, exp. 28. 1665 [Dice 1650]. Real orden para que se dé colación del curato de Teopisca al reverendo padre fray Pedro Román. [16 ff.]. [Folder: San Cristóbal. Ordenes religiosas. Dominicos. 1638-63. XI.A.4.dl. AHDSC, exp. 30, Libro de registro de los despachos de la secretaría episcopal que mandó hacer en 342 fojas el ilustrísimo y reverendísimo señor maes- 
tro don fray Francisco Núnez de la Vega de la orden de predicadores, obispo de esta Ciudad Real de Chiapas y Soconusco, del Consejo de su majestad, en 27 de enero de 1684 años. [Anotación actual: Libro de gobierno. 1683-1730].

\section{Bibliografía citada}

Adams, Robert M., "Patrones de cambio de la organización territorial", Ensayos de antropología en la zona central de Chiapas, N. McQuown y J. PittRivers, editores, México, INI-CNCA, 1989, pp. 43-76.

Aramoni Calderón, Dolores, Los refugios de lo sagrado. Religiosidad, conflicto y resistencia entre los zoques de Chiapas, México, Consejo Nacional para la Cultura y las Artes, 1992.

Calnek, Edward E., "Highland Chiapas Before The Spanish Conquest", Archaeology, Ethnohistory, and Ethnoarchaeology in the Maya Highland's of Chiapas, Mexico, D. D. Bryant, E. E. Calnek, T. A. Lee y B. Hayden, Provo, Utah, New World Archaeological Foundation, 1988.

Calnek, Edward E., "Los pueblos indígenas de las tierras altas", Ensayos de Antropología en la zona central de Chiapas, editado por Normman A. McQuown y Julian Pitt-Rivers, México, INI-CNCA, 1989, pp. 105-133.

Códice Chimalpopoca. Anales de Cuauhtitlan y leyenda de los soles, Traducción directa del náhuatl por P. F. Velázquez, México, UNAM, 1992.

"Despoblación de Xiquipilas, Tacoasintepec, Las Pitas, Coneta, Suchiltepeque, Popocatepeque, Ecatepec, Bachajón, San Andrés, Ixtapilla y Sacualpa (1733-1734)", Boletín del Archivo General de Chiapas, 4, 1955, pp. $25-$ 66. [Edición facsimilar: Documentos históricos de Chiapas, Boletines 34, Tuxtla Gutiérrez, Gobierno del Estado de Chiapas, 1983].

Díaz del Castillo, Bernal, Historia verdadera de la conquista de la Nueva España, México, Porrúa, 1968.

Enríquez, Genoveva, "Nuevos documentos para la demografía histórica de la Audiencia de Guatemala a finales del siglo XVII", Mesoamérica, 17, junio de 1989, pp.121-183.

"Escritura de venta del sitio El Burrero que el bachiller Luis de Estrada dejó en herencia para la fundación de una capellanía a favor de la cofradía de la Concepción del convento de San Francisco de Ciudad Real (1651)", Boletín del Archivo Histórico Diocesano (San Cristóbal de Las Casas), 1, 1981, pp. 15-20. 
Flores Ruiz, Eduardo, Investigaciones históricas sobre Chiapas, San Cristóbal de Las Casas, Patronato Fray Bartolomé de Las Casas, 1973.

García Vargas y Rivera, Manuel, Relaciones de los pueblos del obispado de Chiapas. 1772-1774, Introducción, paleografía y notas de Jorge Luján Muñoz, San Cristóbal de Las Casas, Patronato fray Bartolomé de Las Casas, 1988.

Godoy, Diego, "Relación hecha por Diego Godoy a Hernando Cortés en que trata del descubrimiento de diversas ciudades y provincias, y guerra que tuvo con los indios, y su modo de pelear; de la provincia de Chamula, de los caminos difíciles y peligrosos, y repartimiento que hizo de los pueblos", Historiadores primitivos de Indias, Tomo I, Madrid, (Biblioteca de autores españoles), 1946, pp. 465-470.

Herrera, Antonio de, Historia general de los hechos de los castellanos en las islas y tierra firme del mar océano, Madrid, Imprenta de Nicolás Rodríguez Franco, 1730.

Juarros, Domingo, Compendio de la historia del reino de Guatemala. 15001800, Guatemala, Ed. Piedra Santa, 1981.

Köhler, Ulrich, "Refections on Zinacantan's Role in Aztec Trade with Soconusco", Mesoamerican Communication Routes and Cultural Contacts, Editado por T. A. Lee y C. Navarrete, Provo, Utah, New Worl Archaelogical Foundation, 1978, pp. 67-73.

Lee, Thomas A., "El asentamiento humano precolombino del valle de Hueyzacatlán", San Cristóbal y sus alrededores, 2 vols., Tuxtla Gutiérrez, Gobierno del Estado de Chiapas, 1984, vol II, pp. 151-159.

Lee, Thomas A., "las rutas históricas de Tabasco y el norte de Chiapas", Comercio, comerciantes y rutas de intercambio en el México antiguo, Lorenzo Ochoa, compilador, México, Secretaría de Comercio y Fomento Industrial, 1989, pp. 151-178.

Lenkersdorf, Gudrun, Génesis histórica de Chiapas. 1522-1532. El conflicto entre Portocarrero y Mazariegos, México, UNAM, 1993.

López Sánchez, Hermilo, Apuntes históricos de San Cristóbal de Las Casas, Chiapas, México, 2 vols., México, Edición del autor, 1960.

Megged, Amos, "Accommodation and Resistance of Elites in Transition: The Case of Chiapa in Early Colonial Mesoamerica", Hispanic American Historical Review, 71: 3, 1991, pp. 477-500.

Navarrete, Carlos, "El sistema prehispánico de comunicaciones entre Chiapas y Tabasco (Informe preliminar)", Anales de Antropología, X, 1973, pp. 33-92. 
Navarrete, Carlos, The Chiapanec. History and Culture, Provo, Utah, New Worl Archaelogical Foundation, 1966.

Remesal, Fr. Antonio de, Historia general de las Indias Occidentales y particular de la gobernación de Chiapa y Guatemala, 2 vols., México, [d. Porrúa, 1988.

Reyes García, Luis, "Movimientos demográficos en la población indígena de Chiapas durante la época colonial", La Palabra y el Hombre, 21, 1962, pp. 25-48 [Universidad Veracruzana, Xalapa].

Rus, Jan, y Robert Wasserstrom, "Civil-Religious Hierarchies in Central Chiapas: A Critical Perspective", American Ethnologist, 7 (3), 1980, pp. 466-478.

Ruz, Mario Humberto, Copanaguastla en un espejo. Un pueblo tzeltal en el Virreinato, San Cristóbal de las Casas, CEI-UNACH, 1985.

Ruz, Mario H., "Una probanza de méritos indígenas, Zinacantán, 1621", Tlalocan, XI, 1989, pp. 339-363.

Ruz, Mario Humberto, Chiapas colonial: Dos esbozos documentales, México, UNAM, 1989.

Ruz, Mario H., "Los rostros de la resistencia. Los mayas ante el dominio hispano", Del katún al siglo. Tiempos de colonialismo y resistencia entre los mayas, M. C. León, M. H. Ruz y J. Alejos García, México, CONACULTA, 1992, pp. 85-162.

Sahagún, Fr. Bernardino de, Historia general de las cosas de Nueva España, 2 vols., Introducción, paleografía, glosario y notas de J. García Quintana y A. López Austin, México, CNCA y Alianza Editorial Mexicana, 1989.

Séptimo censo general de población, 6 de junio de 1950. Estado de Chiapas, México, Secretaría de Economía (Dirección General de Estadística), s.f. Tejada Bouscayrol, Mario y John E. Clark, "Los pueblos prehipánicos de Chiapas", Anuario 1992. Instituto Chiapaneco de Cultura, Ocozocoautla, 1993, pp. 325-379.

The Codex Mendoza, 4 vols., Edición de F. F. Berdan y P. Rieff Anawalt, Berkley, Los Angeles y Oxford, University of California Press, 1992.

Vida económica de Tenochtitlan. 1. Pochtecayotl (Arte de traficar), Paleografía, versión, introducción y apéndices de A. M. Garibay K., México, UNAM (Fuentes indigenas de la cultura náhuatl, Informantes de Sahagún, 3), 1961.

Viqueira, Juan Pedro, "Le mythe des colonies préhispaniques nahuas au Chiapas central", Journal de la Société des Américanistes, 83, 1997, pp. 37-58. 
Viqueira, Juan Pedro, Indios rebeldes e idólatras. Dos ensayos históricos sobre la rebelión india de Cancuc, Chiapas, acaecida en el año de 1712, México, Centro de Investigaciones y Estudios Superiores en Antropología Social, 1997.

Vogt, Evon Z., "Algunos aspectos de patrones de poblamiento y de la organización ceremonial de Zinacantán", Los zinacantecos. Un pueblo tzotzil de los altos de Chiapas, Editado por Evon Z. Voght, pp. 63-87, México, INI, 1966.

Vogt, Evon Z., Bibliography of the Harvard Chiapas Project: The First Twenty Years 1957-1977, Massachusetts, Harvard University Press, 1978.

Vogt, Evon Z., Fieldwork among the Maya. Reflections on the Harvard Chiapas Project, Albuquerque, University of New Mexico Press, 1994.

Vos, Jan de, Fray Pedro Lorenzo de la Nada, misionero de Chiapas y Tabasco, en el cuarto centenario de su muerte, México, Ed. del autor, Sin fecha.

Vos, Jan de, La paz de Dios y del Rey. La conquista de la selva lacandona, México, FONAPAS Chiapas (Colección Ceiba), 1980.

Vos, Jan de, La batalla del Sumidero, México, Ed. Katún, 1985.

Vos, Jan de, Vivir en frontera. La experiencia de los indios de Chiapas, México, CIESAS e INI, 1994.

Wasserstrom, Robert, Clase y sociedad en el centro de Chiapas, México, FCE, 1989.

Ximénez, Fr. Francisco, Historia de la provincia de San Vicente de Chiapa y Guatemala de la orden de predicadores, Libros I y II, Guatemala, Sociedad de Geografía e Historia de Guatemala (Biblioteca Goathemala, vol. XXVIII), 1977.

Ximénez, Fr. Francisco, Historia de la provincia de San Vicente de Chiapa y Guatemala de la orden de los Predicadores, Tomo II [Libros IV y V], Guatemala, Sociedad de Geografía e Historia (Biblioteca Goathemala, vol. II), 1930.

Ximénez, Fr. Francisco, Historia de la provincia de San Vicente de Chiapa y Guatemala, orden de predicadores, Libro VI, Guatemala, Sociedad de Geografía e Historia de Guatemala (Biblioteca Goathemala, vol. XXIV), 1971. 


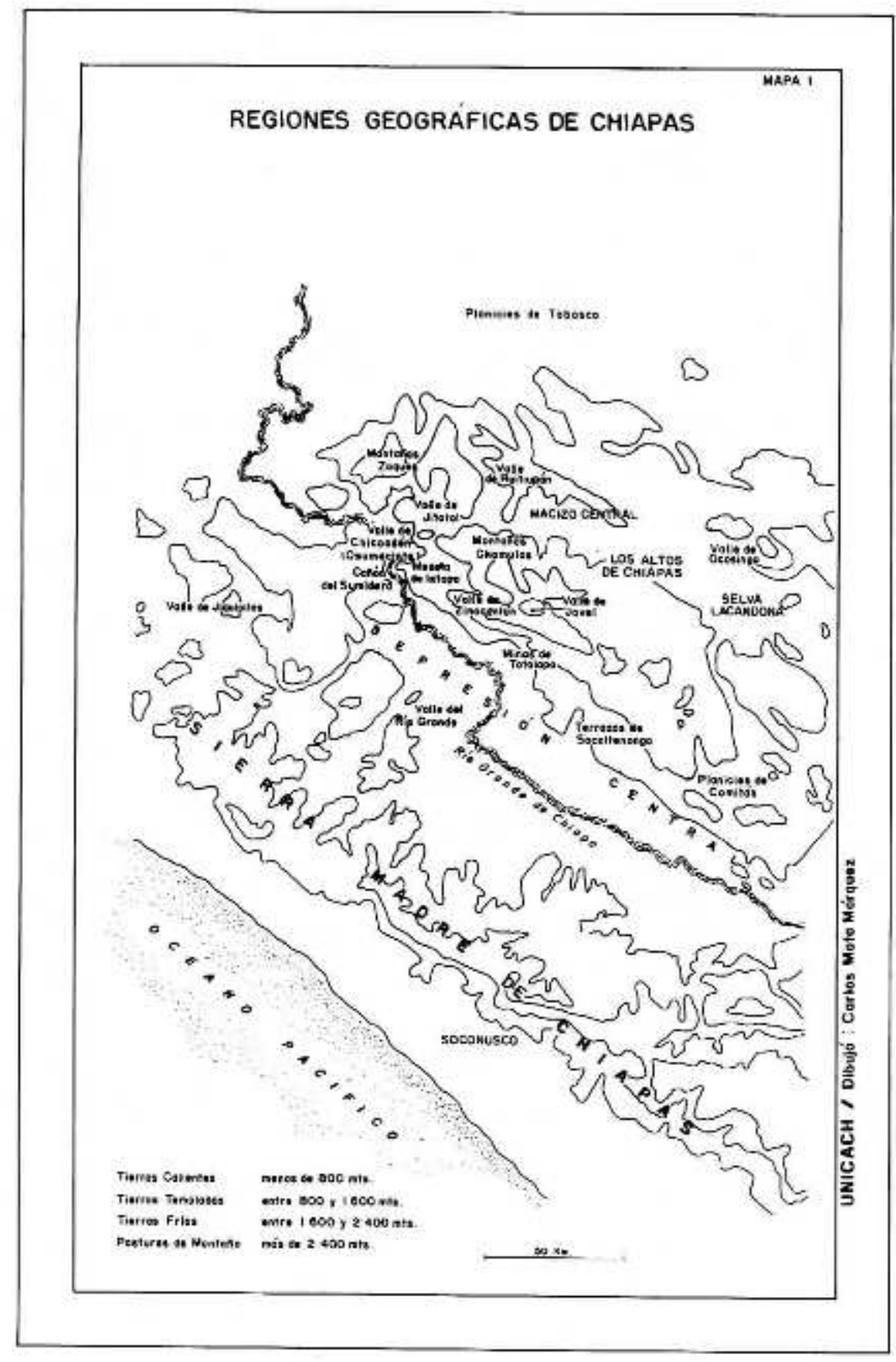




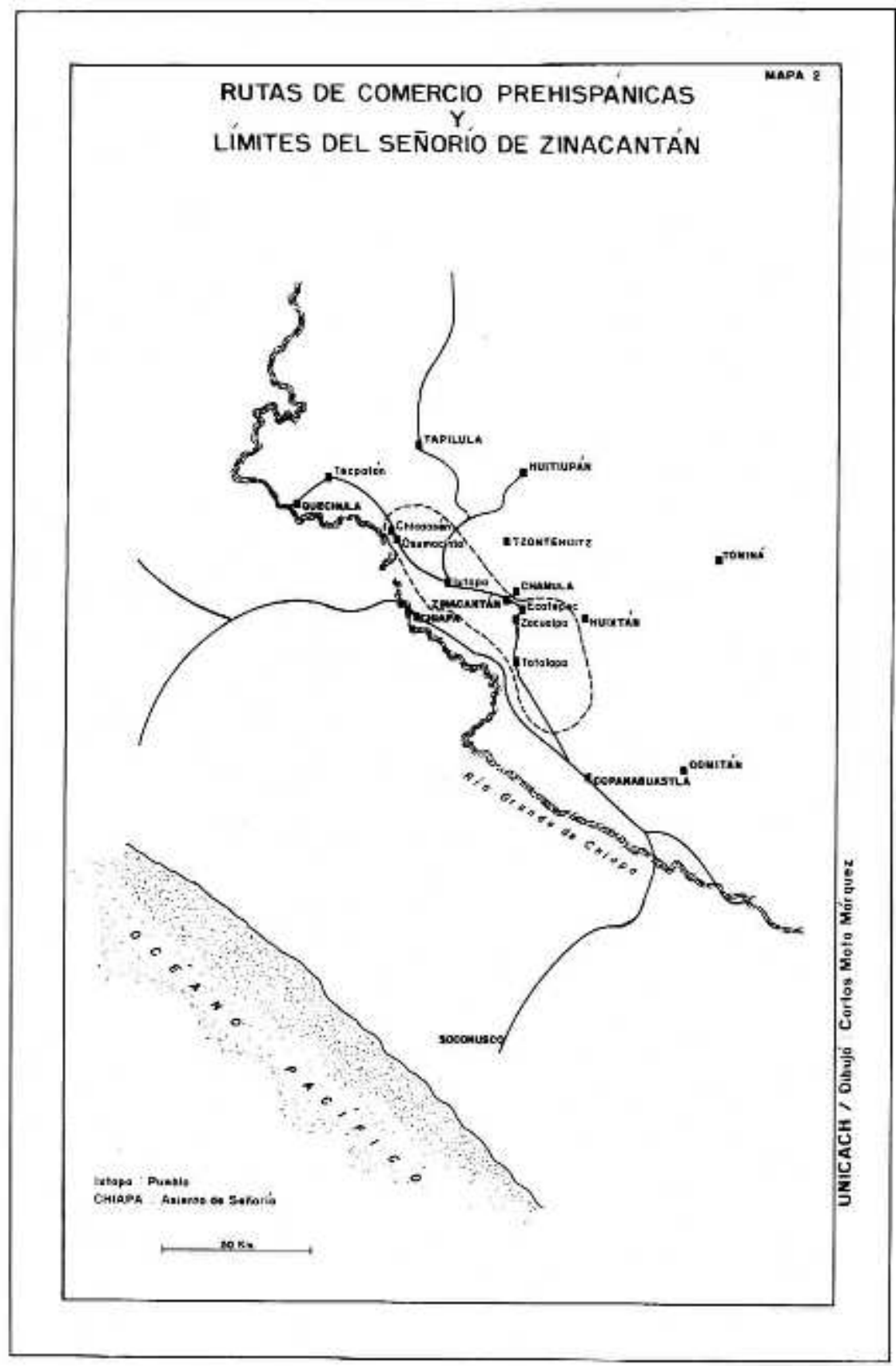




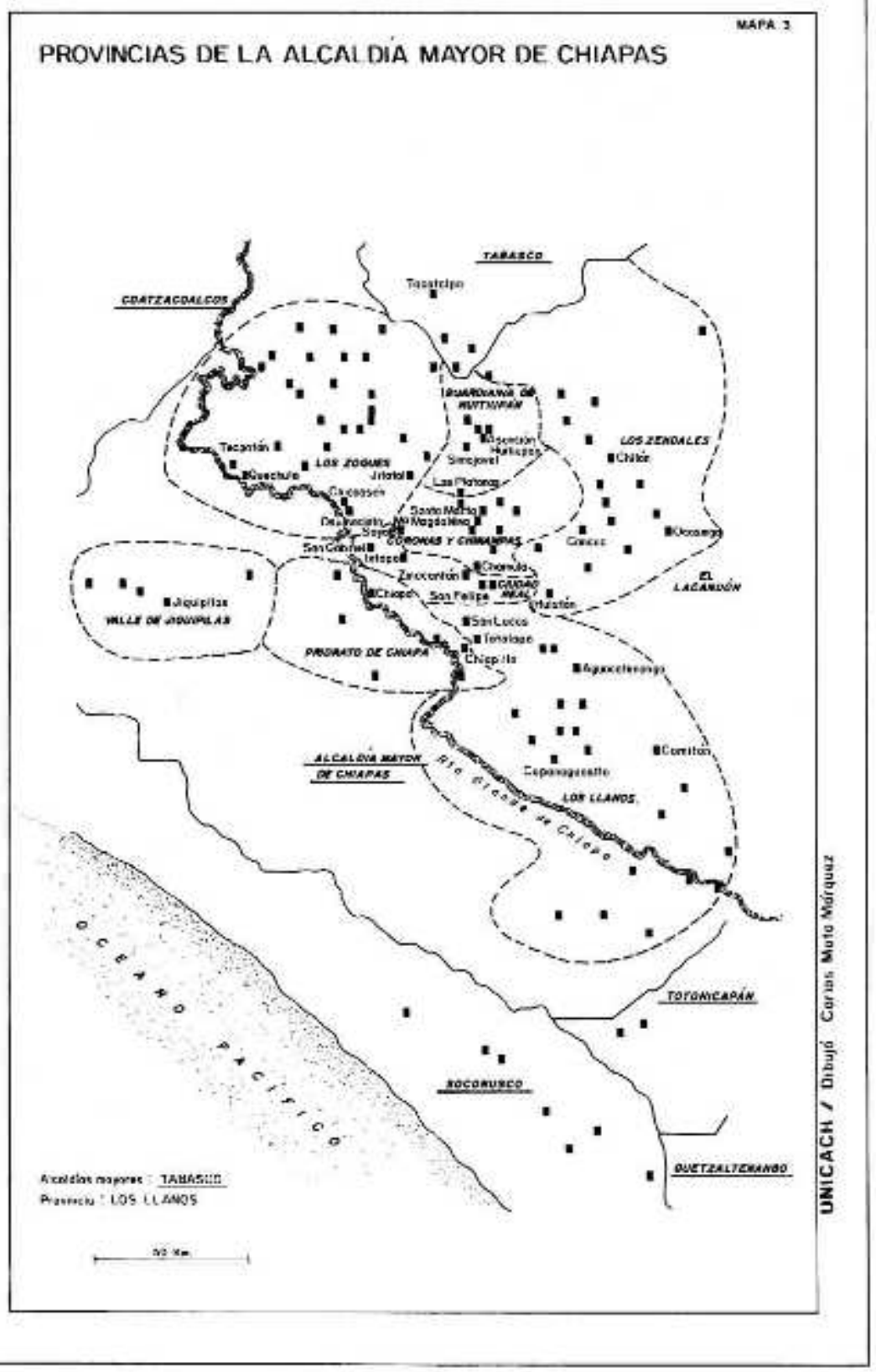

